\title{
A revolução, a luta, a resistência e o povo: os marcadores retóricos dos anos 60
}

\author{
Jacques $A$. Wainberg*
}

\begin{abstract}
Resumo
Os anos 1960 foram marcados por intensa militância política e militar de grupos de jovens rebelados mobilizados por ideias radicais que visavam modificar as sociedades de seus países. Estas ações foram acompanhadas por inúmeros manifestos públicos. Este estudo examinou 25 destes comunicados, selecionou por meio do wordle os verbetes que apresentavam maior frequência e, utilizando o cultoromics, avaliou o uso destes termos na literatura em inglês, francês, espanhol, alemão, russo, chinês e hebraico no período de 1800 a 2000. Percebe-se nos gráficos resultantes não só a diferença entre estas tradições linguísticas e culturais ao longo do tempo como também significativa dissonância entre a retórica dos grupos rebelados e o clima intelectual vigente na década de 1960 e adiante. Palavras chave: Retórica. Anos 60. Discurso. Comunicação Política.
\end{abstract}

Revolution, struggle, resistance and the people: rhetoric markers of the 60's

\section{Abstract}

The 60's were marked by intense political activism and military rebellious of youth groups mobilized by radical ideas aimed at modifying the societies of their countries. These actions were accompanied by numerous public manifestos. This study examined 25 of these communiqué. There were selected through wordle the entries with higher frequency and through cultoromics there were evaluated the use of these terms in the English, French, Spanish, German, Russian, Chi-

* Professor titular do Programa de Pós-Graduação em Comunicação, Faculdade de Comunicação Social da Pontifícia Universidade Católica do Rio Grande do Sul - Porto Alegre, RS, Brasil. É Doutor pela Universidade de São Paulo e pós- doutor pela Universidade do Texas. Autor de vários livros, entre eles Mídia e Terror (Paulus, 2005); Línguas Ferinas (Edipucrs, 2010); Império das Palavras (1997); A Pena, a Tinta e o Sangue - A Guerra das Ideias e o Islã (Edipucrs, 2010). E-mail: Jacqalwa@pucrs.br. 
nese and Hebrew literatures in the period from 1800 to 2000. It can be seen in the resulting graphs the rhetorical differences of these linguistic traditions. It becomes also clear the discrepancy between the political rhetoric of those groups of students and mainstream cultural traditions of the 60's and on.

Key words: Rhetoric. The 60's. Discourse. Political Communication.

\section{La Revolución, la lucha, la resistencia y el pueblo: los marcadores retóricos de los años 60}

\section{Resumen}

Los años 60 estuvieron marcados por una intensa militancia política y militar de los grupos de jóvenes rebeldes movilizados por las ideas radicales dirigidas a modificar las sociedades de sus países. Estas acciones fueron acompañadas por numerosos manifiestos públicos. Este estudio examinó a 25 de estos comunicados. Fueran seleccionados a través de la Wordle las entradas con mayor frecuencia y por cultoromics fue evaluado la utilización de estos términos en la literatura en Inglés, francés, español, alemán, ruso, chino y hebreo en el período 1800 a 2000. Se puede observar en los gráficos resultantes la diferencia retórica de estas tradiciones lingüísticas. También se puede observar la diferencia entre la retórica política de los grupos rebeldes de jóvenes estudiantes y el clima intelectual del período. Palabras clave: La retórica. Los años 60. Discurso. La comunicación política.

\section{Introdução}

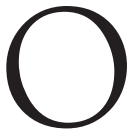

s anos 1960 foram marcados pela ampla difusão das ideias utópicas. Na sua pregação despontaram grupos, indivíduos e movimentos comprometidos com uma espécie de fé no alvorecer de um novo mundo. A resenha destes eventos mostra o tom dramático que esta ampla e diversificada disputa ideológica pelo controle do imaginário social assumiu naqueles anos. No ocidente e no oriente, se engalfinharam na batalha por corações e mentes o liberalismo, o comunismo, o feminismo e o pacifismo, principalmente. O nascimento do movimento ambientalista naquela época também ofereceu razões e justificativas para protestos dos críticos.

Os estudantes foram os porta-vozes de um incômodo que atingiu por razões distintas as sociedades de diferentes países. Em cada um deles, havia um ou mais de um tipo de dilema sem solução que acabaria derivando muitas vezes para a violência política. À época, amplo leque de movimentos contrários ao establishment cultural igualmente se desenvolveu. Sempre havia alguém ou algo 
disponível para se odiar. É como se os jovens do mundo estivessem se dirigindo ao mesmo tempo às barricadas.

Em boa medida, este comportamento similar dos jovens em todo o mundo foi resultado do impacto causado pela transmissão destes eventos pela televisão. $\mathrm{O}$ vídeo-tape permitiu que estas ocorrências fossem vistas por todos quase ao mesmo tempo e numa velocidade que se aproximava da instantaneidade. Tal efeito contágio das mentes tem sido assinalado por vários remanescentes desta época. Por exemplo, os violentos choques entre os estudantes das universidades de Berkeley e Columbia e a polícia norte-americana foram algumas das marcantes e dramáticas ocorrências que impulsionaram este mimetismo dos estudantes em boa parte do mundo. Os atores políticos da época logo entenderam o papel social e político da nova tecnologia de comunicação. Os grupos radicais aprenderam também a manipular a linguagem do veículo oferecendo aos repórteres cinematográficos cenas dramáticas de protesto e violência.

A mídia exerceria igualmente seu novo papel de difusor de modas políticas e de ideias de protesto e de revolução na cobertura que realizou das manifestações dos jovens franceses a partir de maio de 1968. Os enragés rapidamente cresceram em número e ferocidade. Suas reivindicações passaram das queixas estudantis contra as más condições do campus suburbano para protestos generalizados contra a Guerra do Vietnã. A Sorbonne tomada pelos rebelados acabaria invadida pela polícia.

Já o caso alemão foi especialmente grave porque testemunhou a ação de grupos de extrema-esquerda que decidiram utilizar táticas e ações de terrorismo político no coração da Europa. $\bigcirc$ que estava em jogo era a profunda descrença de jovens alemães de classe média à nova sociedade que emergia no país após a Segunda Guerra Mundial, em especial aos seus valores capitalistas e à aliança estratégica que o governo do país tinha estabelecido com os Estados Unidos. Na Itália, a facção de extrema-esquerda Brigada Vermelha (BV), fundada por Renato Curcio, um estudante da Universidade de Trento, expressaria por meio da radicalidade de seus atos desgosto similar à sociedade capitalista do ocidente. Também no Japão atuaria na mesma época outra versão deste mesmo tipo 
de exército de jovens universitários dedicados à construção pela força da sociedade comunista imaginada como redentora. O Exército Vermelho Japonês (EVJ) local atacaria delegacias de polícia e bancos, e após a fuga de seus dirigentes ao Líbano, atingiriam alvos civis igualmente.

A Revolução Cultural na China, a rebelião cubana liderada por Che Guevara e Fidel Castro e a revolução comunista liderada pelos bolcheviques em 1917 na Rússia conferira mágica reputação à ação violenta como alternativa redentora. Ela influenciou também grupos latino-americanos como são os casos do VAR-Palmares, da Ação Libertadora Nacional, da Vanguarda Popular Revolucionária e do Movimento Revolucionário 8 de Outubro no Brasil; o dos Montoneros, na Argentina; o dos Tupamaros no Uruguai e dos maoístas do Sendero Luminoso que passaram a atuar no Peru a partir de 1970 .

\section{Nostalgia}

Pode-se afirmar que uma geração pode nutrir-se do comportamento de outras perdidas no tempo. Este é o caso do fascínio exercido sobre os jovens do século 21 pelos feitos da geração dos anos 1960. Ele deriva em boa medida da aparência heróica, emotividade e violência das ocorrências daquela década insufladas pelas ideias redentoras. Naquele tipo de ambiente, o discurso utópico floresceu nutrindo-se algumas vezes de crises reais e noutras dos sonhos da juventude. Estes fatores ajudaram a amplificar a natural dissonância dos universitários com seu ambiente. O discurso de tom messiânico ajudou a inflamar os ânimos causando no público juvenil grau crescente de desconforto com o estado do mundo. A produção deste efeito de estranhamento ao ambiente circundante é missão usual da crítica social. O resultado mais sofisticado deste tipo de impacto tem sido a formulação do que se convencionou denominar de espírito revolucionário dos militantes. Em inúmeros casos ele autorizou a ação política subversiva e o terrorismo. Vislumbrando as utopias desejadas, estes reformadores sociais acabaram decidindo construir o novo homem a ferro e fogo. 
Segundo Paul Hollander (1997), para que a ilusão se consolide em torno de um objeto de veneração, ele deve ser capaz de articular os descontentes em suas próprias sociedades. A utopia deve ser razoavelmente distante e desconhecida dos crentes. $\mathrm{O}$ sonho deve ainda ser capaz de cultivar na pessoa uma imagem de vítima. Por fim, a utopia deve ser hostil à sociedade liberal do ocidente. Outro autor, Richard E. Nisbett (2004), diz que as utopias ocidentais têm cinco características centrais. A história é vista como uma jornada segura e mais ou menos linear rumo à sociedade perfeita. Ao fim e ao cabo a realização deste sonho político deve se tornar permanente. É como se a história estancasse e chegasse ao fim. Ainda, a utopia resulta do esforço humano. Ela não decorre nem do destino nem da intervenção divina. Ela geralmente apresenta um ideário igualitário e está baseada em alguns pressupostos radicais da natureza humana.

A verdade é que, de uma forma geral, para os espíritos mais inquietos, 'a desordem natural das coisas' nunca foi bem-vinda. A ambição utópica sempre desejou 'consertar o mundo' de alguma maneira e de forma definitiva. Este termo - conserto do mundo

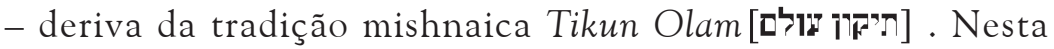
tradição, este clamor por ação retificadora não emanou de uma lei bíblica, mas do desejo humano de evitar o caos social. Na origem, o termo foi utilizado pelos tribunais rabínicos para cancelar feitos considerados perniciosos ao interesse público. Até assumir sua conotação secularizada contemporânea houve várias outras utilizações desta ideia. Em última instância, ela buscava motivar as pessoas a construírem uma sociedade modelo, uma sociedade sem falsos deuses - como propõe a prece Aleinu na qual o termo acabou incluído.

\section{A obra utópica}

A verdade é que é difícil não sonhar. Thomas More (14781535), por exemplo, criou a mágica ilha da Utopia em seu livro "De optimo reipublicae statu deque nova insula Utopia" escrita em 1516 (1964). Algo similar pode ser percebido na República de Platão (427-347 a.C.). Já o (assim rotulado) socialismo utópico 
transformou as palavras de Marx numa experiência laboratorial deste novo mundo. Saint-Simon, Étienne Cabet, Charles Fourier e Pierre Joseph Proudhon foram alguns de seus protagonistas.

Como dito, a ideia do Éden não era nova a esta gente toda. Esta utopia surgira originalmente na forma do mito do Jardim de Dilmun (2500 a.C), também conhecido como 'o local onde nasce o sol' e como a 'Terra dos Vivos'. Segundo esta narrativa sumeriana, neste local Noé foi acolhido pelos deuses para viver eternamente. Sonho similar tinha sido expresso por Hesíodo que elaborou no século VIII a.C. sobre a Era de Ouro que teria existido no distante passado. Já a região de Arcádia, localizada na região grega do Peloponeso, passou a ser sinônimo de uma região idílica rural em harmonia com a natureza. Também a Terra de Cocaigne referiu-se a um reino imaginário e maravilhoso. Algo similar teria existido em Xangrilá, a mítica localidade descrita em 1933 na novela Horizonte Perdido, do britânico James Hilton (1980). Neste isolado e paradisíaco vale do Tibete as pessoas eram imortais. Em sua chegada à América, Cristóvão Colombo pensou ter encontrado finalmente um destes paraísos consumidos então pelo imaginário popular.

Teria havido também uma cidade - Cristianópolis (que deu nome a um município do estado de Goiás) - na qual uma irmandade especial possuía uma sabedoria secreta que lhe permitia inclusive fazer experimentações científicas a fim de revelar os segredos da natureza. O autor desta narrativa (1999) foi o luterano Johann Valentin Andreae (1585-1654). Era um profícuo divulgador de panfletos (Fama Fraternitatis e Confessio Fraternitatis) por meio dos quais divulgava suas fantasias sobre uma perfeita comunidade cristã.

Tais cenários imaginados que inspiraram obras de ficção literária motivaram também fluxos imigratórios e iniciativas sociais variadas. Por exemplo, a chegada de 296 finlandeses entre setembro de 1927 e 16 de outubro de 1940 à localidade de Penedo, no Estado do Rio de Janeiro, é exemplo deste tipo de fervor utópico que demanda a construção de uma modalidade inovadora de vida comunitária, às vezes provocada por intensa fé religiosa ou ideológica. Além do exemplo finlandês, há vários outros em várias partes do mundo. É o caso dos Shakers, por exemplo. O grupo foi formado no século 18 
por dissidentes de várias religiões, entre eles os quakers ingleses e os metodistas. Os shakers emigraram aos Estados Unidos em 1774, estabelecendo-se em várias localidades do país.

Além das idealizações ocidentais as utopias foram igualmente produto de outras civilizações. No caso da China destaca-se Tao Yuanming (1993), autor da obra de ficção Tao Hua Yuan (421) (A Colônia dos Pêssegos), um lugar imaginado e utópico onde as pessoas vivem em absoluta harmonia. Outro estado ideal à semelhança do elaborado por Platão foi proposto em Al-Madina al-Fadila (1985), escrito por Al-Farabi (874-950). Já Islândia (1942) foi uma ilha imaginária proposta pelo autor americano Austin Tappan Wright no hemisfério sul (2006). Outros exemplos incluem Big Planet de Jack Vance (2002); Ecotopia de Ernest Callenbach (2004); Woman on the Edge of Time de Marge Piercy (1985). Sua polêmica novela 'Walden II: Uma Sociedade do Futuro' descreve uma comunidade rural de 1000 membros em que todos os aspectos da vida são condicionados por princípios comportamentalistas, em especial o reforço positivo. Este tipo de ideia fez surgir a comunidade de Los Horcones no México.

Tais sonhos não foram estranhos à mitologia e aos filósofos gregos. O poeta romano Virgílio (70-19 a.C) sugere em seu poema Ecloga IV (1959) que o progresso pode produzir um mundo mais afluente e perfeito. Hesíodo (VII a.C), por sua vez, elaborou sobre As Cinco Eras da Humanidade. Também Ateneu refere-se em sua obra Os Gastrônomos ao poeta cômico Telecleides que elabora satiricamente sobre a existência de uma antiga e desaparecida Era de Ouro. Bem mais tarde, o filósofo e escritor italiano Tomaso Campanella (1568-1639), escreveu durante sua prisão (devido a suas ideias políticas radicais) a obra A Cidade do Sol (1990). Na mesma época, outra utopia, Nova Atlântida (1989), foi descrita pelo inglês Francis Bacon (1561-1626). Estas ilhas e lugares isolados, como que afastados do perigo do contágio às fraquezas humanas, permitia aos autores imaginar soluções laboratoriais aos problemas humanos. Tais receituários messiânicos cederam lugar no século 18 ao espírito prático e revolucionário. Chegara a hora, finalmente, de transformar o sonho em realidade. Os homens de ação, desde então, estiveram sempre bem 
acompanhados por pensadores que alimentavam com ideias os disparos de suas armas.

O filósofo francês Antoine-Nicholas de Condorcet (17431794), por exemplo, disseminou sua crença na razão e no destino da humanidade à perfeição. Mais recentemente outra descrição deste tipo, A Moderna Utopia (2011), foi publicada pelo novelista inglês, H. G. Wells em 1905. Este novo mundo teria surgido num planeta similar à Terra. Nele as pessoas criaram uma sociedade perfeita onde os problemas humanos tinham sido finalmente resolvidos.

Este tipo de retórica profética tem sido capaz de derrubar governos. Graças a ela o Rei George III da Grã-Bretanha perdeu suas colônias. E o rei francês Luis XVI o seu pescoço (em 1792).

\section{A pretensão revolucionária}

É verdade que estes fatos e muitos outros fazem pensar sobre a emergência da violência política e também do terrorismo que com frequência emergem nestes golpes com pretensão revolucionária. Foi o que aconteceu no Uruguai em 1963, quando os estudantes locais criaram o Movimento de Libertação Nacional, mais conhecido por Tupamaro. A luta armada deste grupo contra o governo e regime político do país foi capaz de reunir de forma pioneira os elementos simbólicos que acabariam marcando a atitude da juventude inconformada dos anos 60 em várias partes do mundo.

No caso chileno, o MIR (Movimento da Esquerda Revolucionária) foi fundado em 1965. Vários grupamentos de esquerda (trotskistas, maoístas, stalinistas, anarquistas e libertários, entre outros) acabaram repetindo a fórmula utilizada pelos tupamaros uruguaios. O grupo chileno se auto-definiu como um partido de vanguarda que advogava o modelo revolucionário marxista-leninista que visava implantar uma 'ditadura do proletariado' comunista no país. Como noutros casos similares, estes jovens de 22 a 26 anos, muitos deles originários da Universidade de Concepción, foram fortemente influenciados pelos ensinamentos dos filósofos da Escola de Frankfurt, pela Nova Esquerda norte-americana, pela Revolução Cubana e pelo ambiente de disputas ideológicas e militares da Guerra Fria. Sua plataforma repudiava o terrorismo 
político, muito embora grupos dissidentes tenham realizado ao longo do tempo vários ataques armados contra inimigos políticos. Em 1969, ele se torna clandestino para evitar a perseguição policial. Já o MIR peruano nasceu em 1962. Definiu-se de imediato como marxista e como os demais ele sofreu forte influência da revolução cubana. Por isso mesmo iniciou operações de guerrilha contra o governo em 1965. Suas dissidências acabaram formando outras organizações igualmente radicais que visavam implantar no país a nova sociedade prometida nos escritos revolucionários. De todas estas experiências latino-americanas, a mais dramática por seus efeitos e consequências foi a argentina. Neste país jovens estudantes fundariam em 1968 o grupo Montoneros cuja ideologia inspirada no peronismo sofreu forte influência da teologia da libertação e do marxismo.

Embate igualmente radicalizado ocorreria na Alemanha. Ele tornou-se famoso pelas violentas ações e o radicalismo ideológico dos militantes da Facção do Exército Vermelho (FEV), também conhecido como Baader-Meinhof. Foram os primeiros a ganharem notoriedade e a projetarem uma imagem pública nacional e internacional graças em especial à televisão. Este grupo originou-se em parte dos remanescentes dos assim denominados 'tupamaros alemães'. Outra parte surgiu dos remanescentes da Kommune 1 (ou K1), uma iniciativa de vida comunitária criada em 1967 (dissolveu-se em 1969) por estudantes. Esta comuna tinha como objetivo desenvolver um estilo de vida distinto ao que era usual na tradicional família conservadora de classe média do país. Entre seus argumentos estava a ideia de que o fascismo se desenvolve no seio da família nuclear. Homens e mulheres deveriam viver separadamente de forma que pudessem se desenvolver livres como pessoas. O grupo advogava a ideia de que a família tradicional deveria desaparecer. Desejavam igualmente eliminar totalmente a propriedade privada entre eles. Para estes jovens o trabalho deveria unicamente ser realizado para satisfazer o prazer de cada um.

No Brasil o ambiente igualmente se radicalizou nos anos 1960. As autoridades do período calculavam a existência de pelo menos 145 grupos, partidos e movimentos cuja militância visava implantar uma sociedade comunista/socialista no país. 


\section{Ação direta e propaganda pelos fatos}

O terrorismo político praticado por vários destes grupos, além de outros, tem sido utilizado intensamente por militantes ao longo da história porque é eficiente. Ela é um tipo de ação direta na qual a comunicação não resulta das palavras, mas dos fatos. Este tipo de ataque lida em última instância com valores, crenças e ideias. Almeja influenciar as atitudes de um público atônito que se divide no exame do significado do ato mortífero. A experiência anarquista do passado popularizou esta estratégia de 'propaganda pelos fatos' e por 'ação direta' almejando mobilizar os aliados e inspirar a 'revolução'.

A história de ambos os conceitos - 'ação direta' e 'propaganda pelos fatos' - é relativamente antiga. Carlos Piscane (1818-57), líder da esquerda durante o Risorgimento italiano, diz em seu Testamento Político que "as ideias surgem dos fatos e não ao contrário”. Mikhail Bakunin (1814-1876) lhe acompanhou o passo. Diria que os princípios devem ser disseminados não com palavras, mas com fatos que se tornam aos olhos dos observadores uma forma mais potente e 'irresistível de propaganda'. O conceito foi popularizado pelo anarquista francês Paul Brousse (1844-1912) que em seus escritos jornalísticos referiu-se à Comuna de Paris, entre outras ocorrências, como exemplo da ação direta e de seu efeito persuasivo sobre o clima de opinião pública. $\bigcirc$ alemão Gustav Landauer (1870-1919) definiu 'a ação direta' como uma maneira de inspirar as pessoas a transformar a sociedade (2010). Entre as táticas utilizadas nestas ações violentas popularizou-se também o assalto aos ricos. Deriva dai também a justificativa que estes círculos deram ao roubo de bancos - denominado por eles de 'expropriação'. O conceito de 'ação direta' explica também os assassinatos políticos, das greves gerais e dos quebra-quebras realizados por grupos subalternos contra os agentes e representantes das classes denominadas por eles de 'privilegiadas'.

É inegável a relação existente entre a prática terrorista destes pioneiros com a dos ativistas de esquerda dos anos 60 e a dos militantes do fundamentalismo islâmico mais recentemente. Todos aprenderam bem a lição de que criando uma 'situação' dramática 
pode-se (1) disseminar com alguma facilidade por todo o mundo uma mensagem e (2) pode-se criar uma crise intelectual e existencial que gera no público a dúvida, a incerteza e a reflexão profunda sobre os fundamentos da sociedade. Segundo esta lógica, os fatos falam por si.

Exemplo mais recente deste tipo de operação de 'propaganda pelos fatos' é o terror suicida. Os Tigres Tâmeis que lutam desde 1976 pela criação de um estado tâmil independente no nordeste de Sri Lanka é o que mais realizou incursões deste tipo. Tornou-se mundialmente conhecido por cometer atrocidades contra civis, assassinato de autoridades e por recrutar crianças-soldado. Foi pioneiro na utilização recente de homens e mulheres-bomba. Este tipo de golpe foi imitado e praticado a seguir por organizações islâmicas variadas que tem justificado suas ações com a figura do martírio religioso. Esta ideia do auto-sacrifício tem sido uma marca geral que tem acompanhado os combatentes, muitos deles suicidas. Foi praticado por pilotos japoneses que guiavam manualmente os torpedos e que se explodiam com o petardo junto ao alvo no período da Segunda Guerra Mundial; pela Luftwaffe, que atacou com missões deste tipo pontes soviéticas localizadas sobre o Rio Oder e por voluntários suicidas integrantes do Viet Minh que atacaram no Vietnã as tropas francesas com cinturões de explosivos colados ao corpo.

\section{Método}

O objetivo deste estudo é averiguar a história do uso de alguns verbetes proeminentes que servem como marcadores da retórica dos grupos rebelados dos anos 60. Estes termos foram selecionados no exame da frequência das palavras utilizadas em dez manifestos divulgados pelos Montoneros e em 15 outros difundidos pelo grupo Baader-Meinhof. $\mathrm{O}$ exame da frequência destes documentos constituídos por 28.924 palavras foi feita por meio do wordle. Já a história do uso dos verbetes na prosa dos autores resulta do exame estatístico realizado pelo culturomics. Trata-se de um novo método de investigação assim batizado por seus inventores do MIT. Por meio do culturomics é possível observar as frequências na 
utilização de certas palavras ou frases no período de 1800 a 2000. Para tanto, tomou-se por base uma amostra de 5.195.769 livros digitalizados. Estes livros correspondem a 4\% de todas as obras já publicadas. Pode-se assim, ao se examinar estes vocábulos considerados como marcadores de uma época e revelar as tendências culturais de períodos variados. A amostra aqui utilizada possui dois bilhões de palavras e frases escritas em sete línguas (inglês, alemão, francês, espanhol, chinês, hebraico e russo), o que corresponde às línguas faladas por $32 \%$ da população do mundo. A fonte do corpus aqui considerado é o banco de dados produzido pelo Google Books. Ele possui 15 milhões de livros digitalizados (12\% de todos os livros publicados), o que equivale a 500 bilhões de palavras, sendo 361 bilhões em inglês, 45 bilhões em francês, 45 bilhões em espanhol, 37 bilhões em alemão, 13 bilhões em chinês, 35 bilhões em russo e dois bilhões em hebraico. ${ }^{1}$

\section{Evidências}

O termo revolucionário é o primeiro evidenciado - e por isso selecionado - na amostra dos termos mais frequentes na prosa dos militantes dos anos 60.

INGLÊS

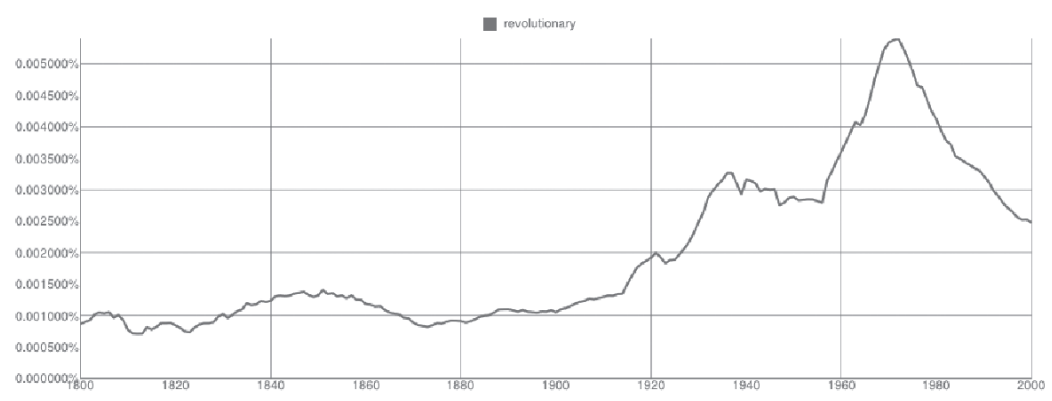

\footnotetext{
${ }^{1}$ Veja Jean-Baptiste Michel, Yuan Kui Shen, Aviva Presser Aiden, Adrian Veres, Matthew K. Gray, The Google Books Team, Joseph P. Pickett, Dale Hoiberg, Dan Clancy, Peter Norvig, Jon Orwant, Steven Pinker, Martin A. Nowak, and Erez Lieberman Aiden. "Quantitative Analysis of Culture Using Millions of Digitized Books”. Science 12/16/2010.
} 
FRANCÊS

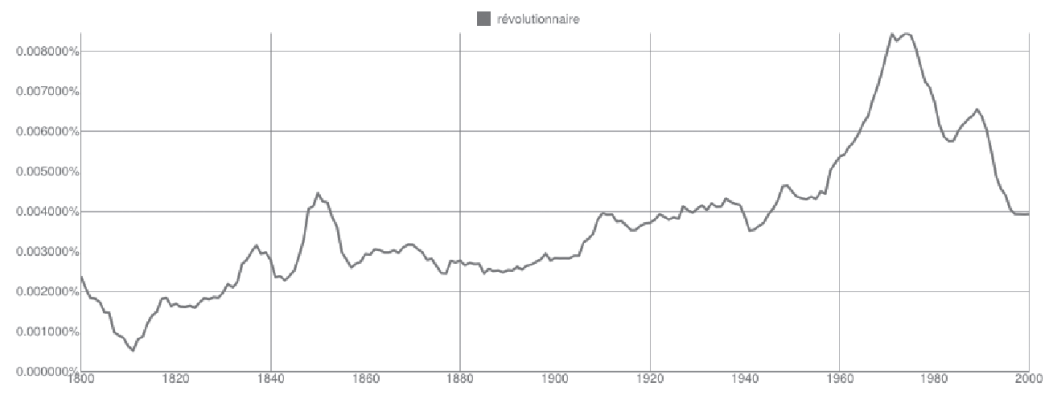

\section{Alemão}

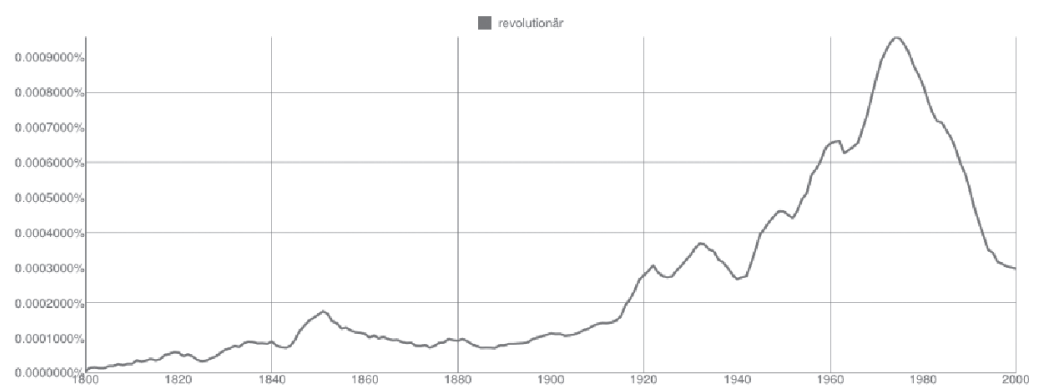

\section{Russo}

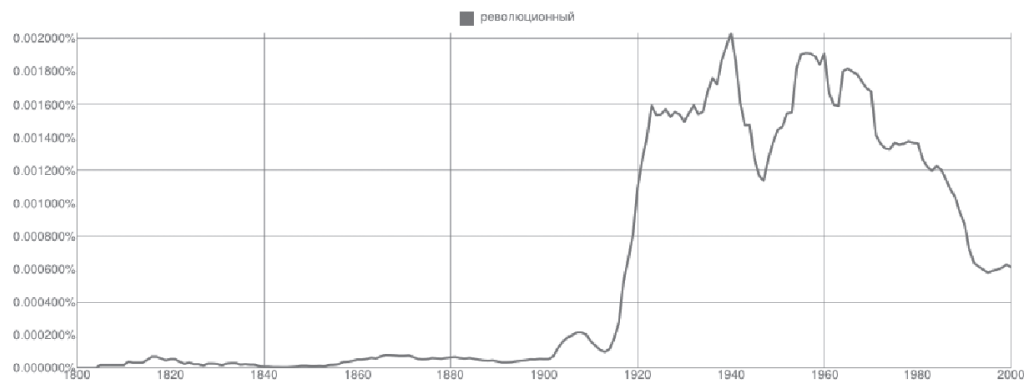


ESPANHOL

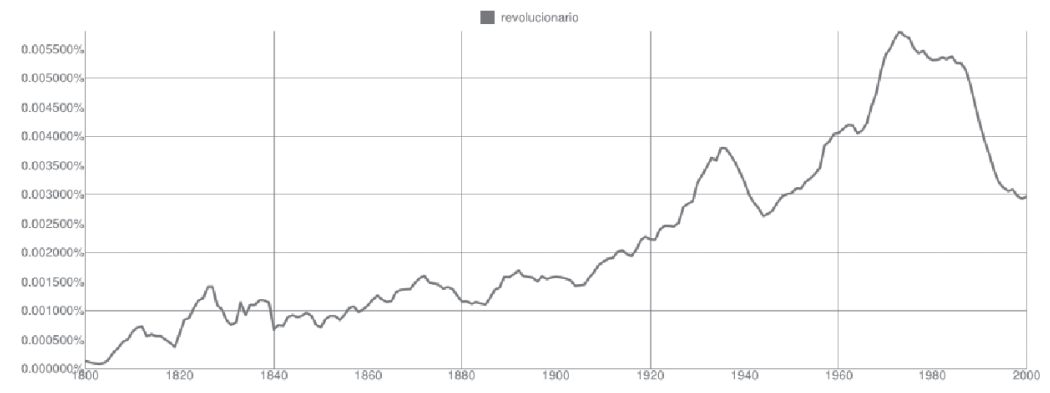

Chinês (SIMPLificADO)

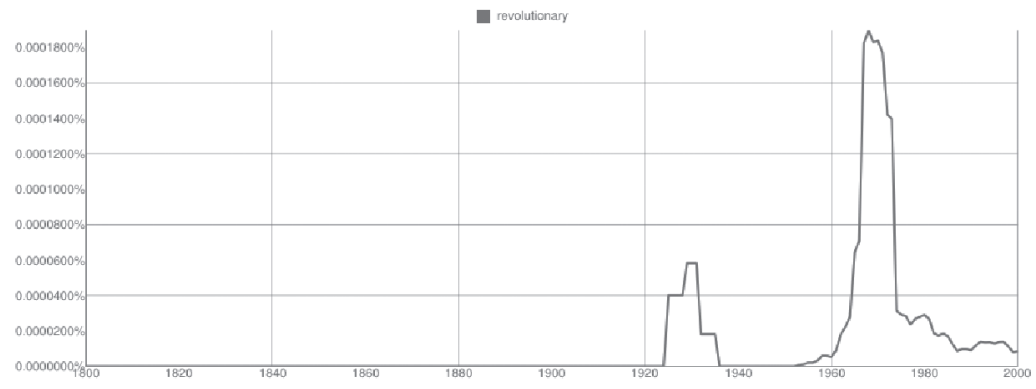

\section{Hebraico}

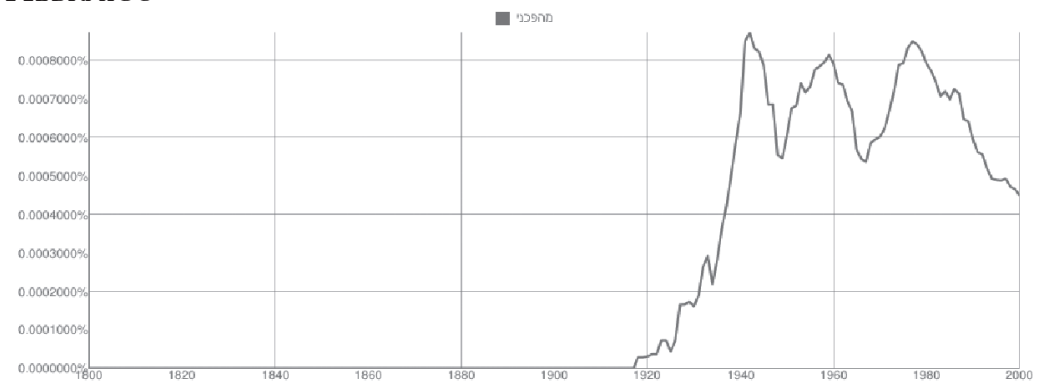




\section{O termo povo é o segundo.}

INGLÊS

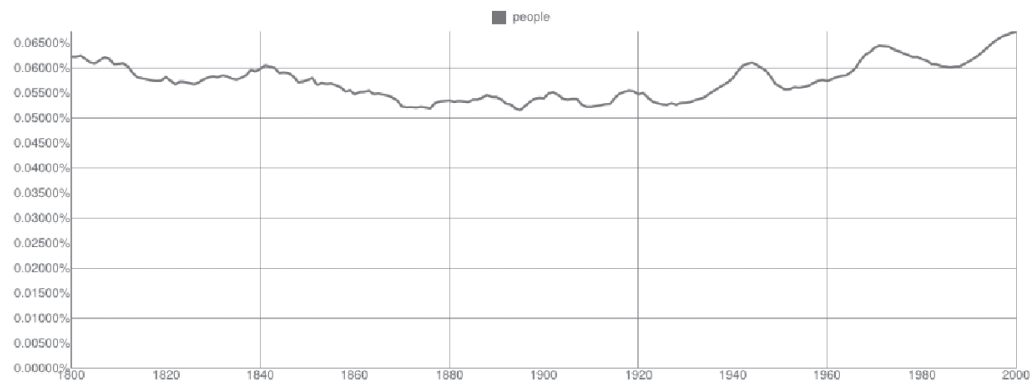

FRANCÊS

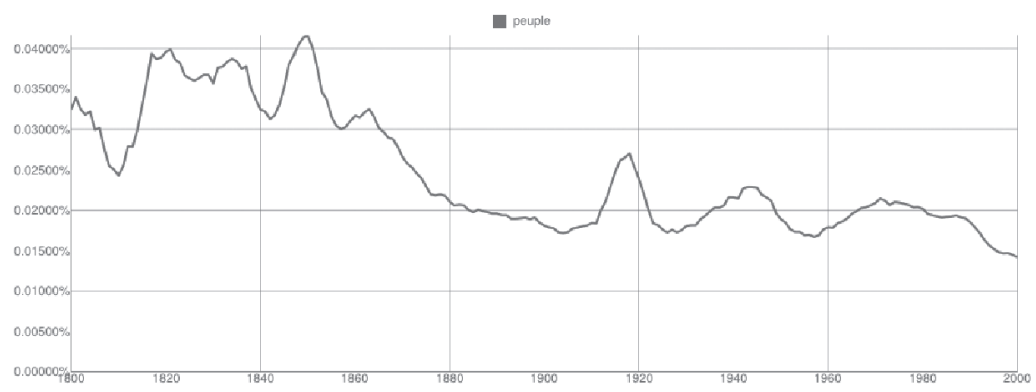

Alemão

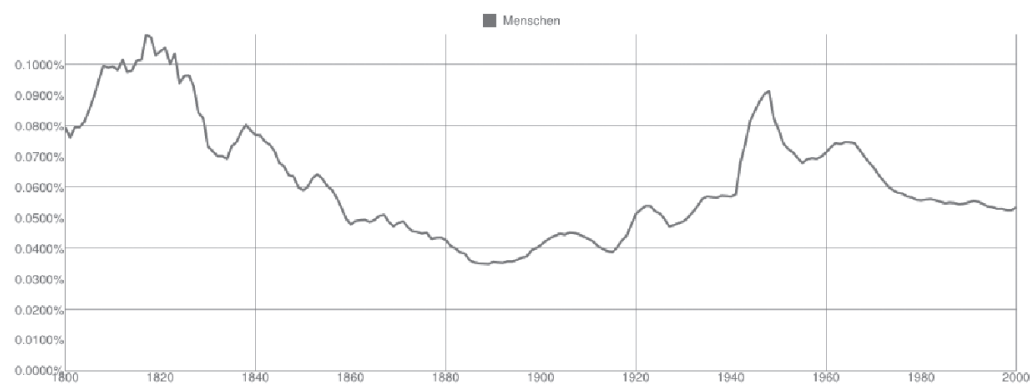




\section{Russo}

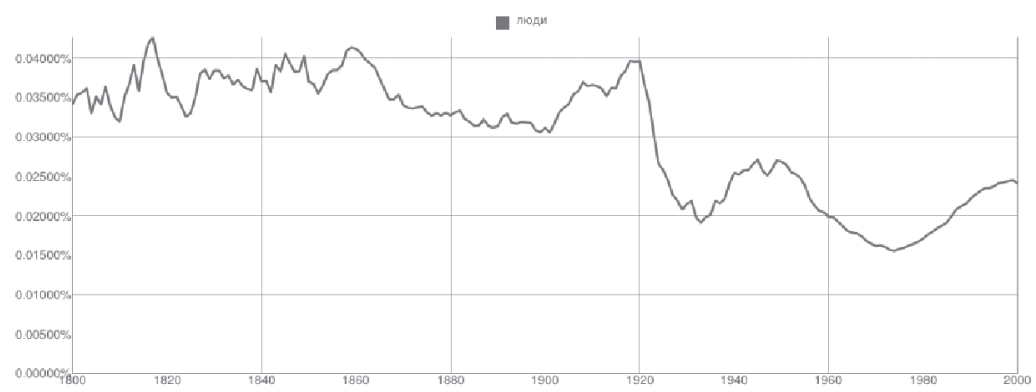

ESPANHOL

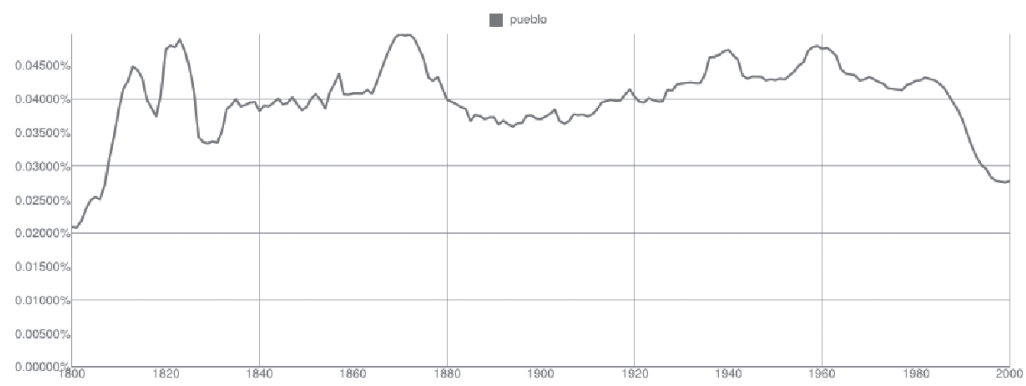

ChinÊs (SIMPLIFICADO)

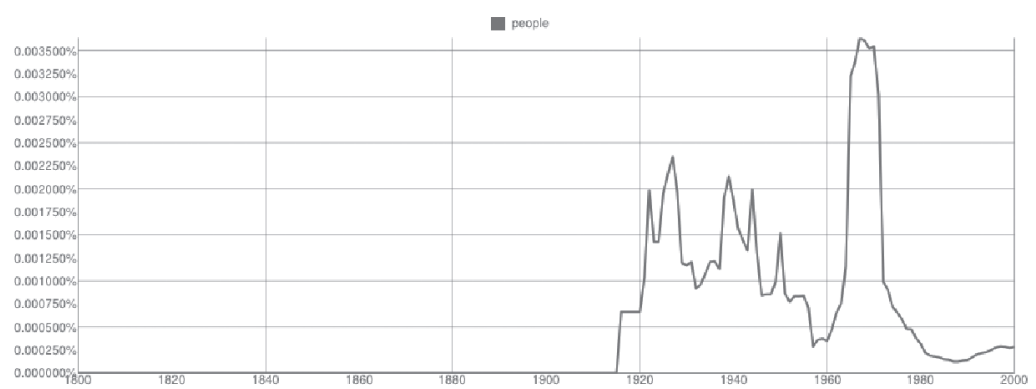


Hebraico

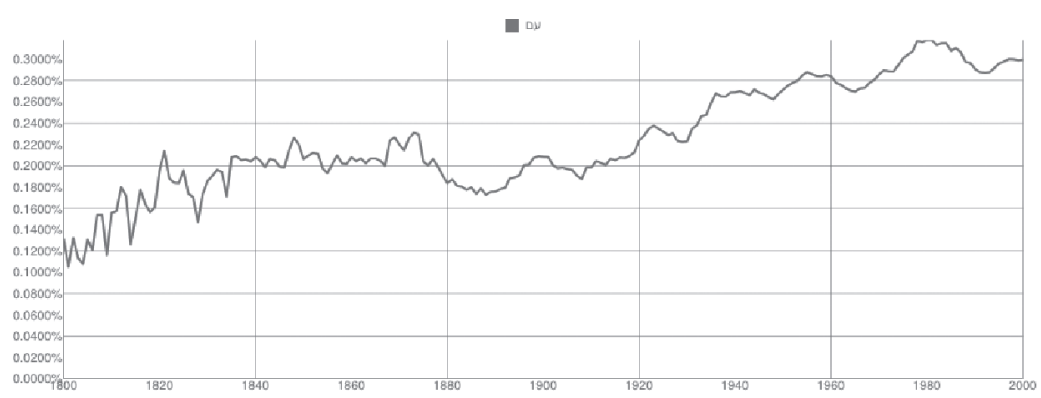

\section{O termo resistência é o terceiro.}

\section{Russo}

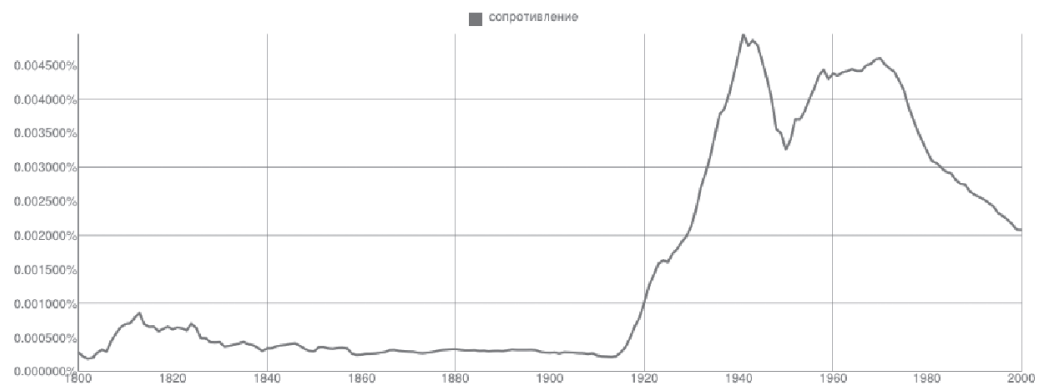

ESPANHOL

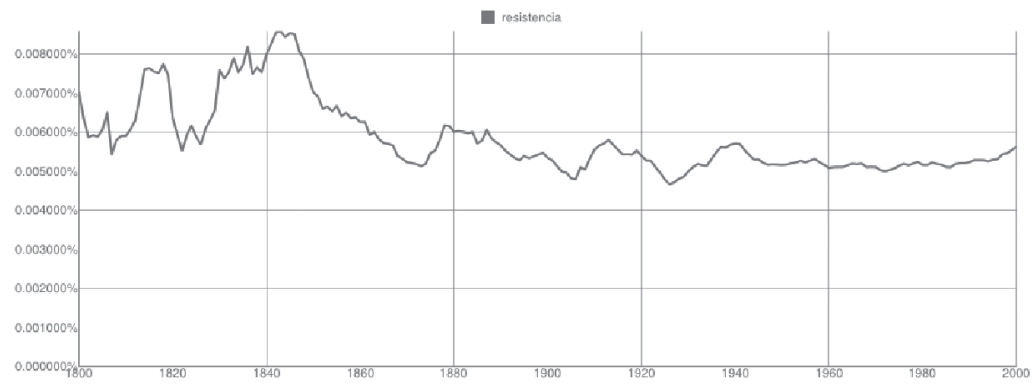


INGLÊS

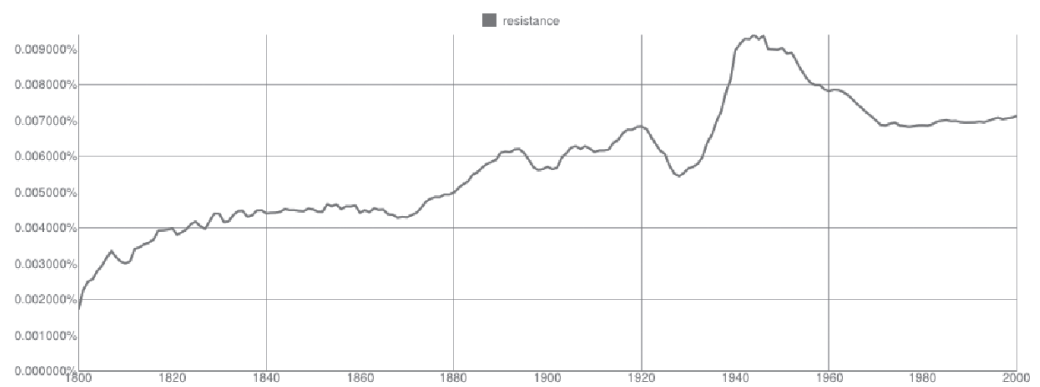

FRANCÊS

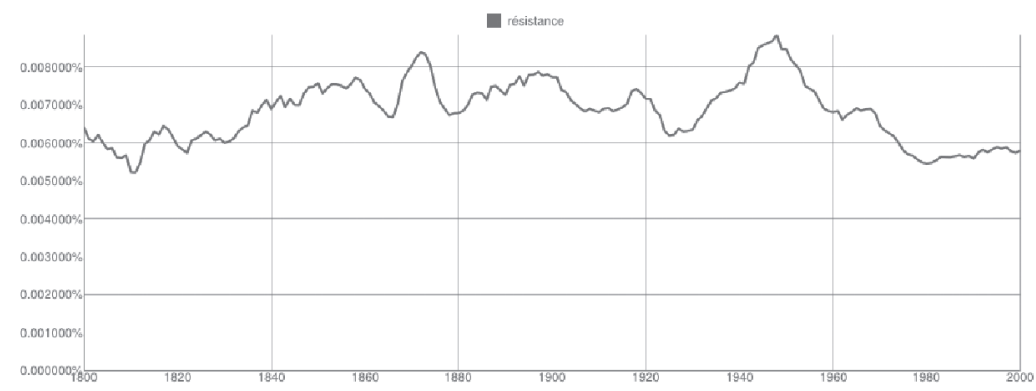

Alemão

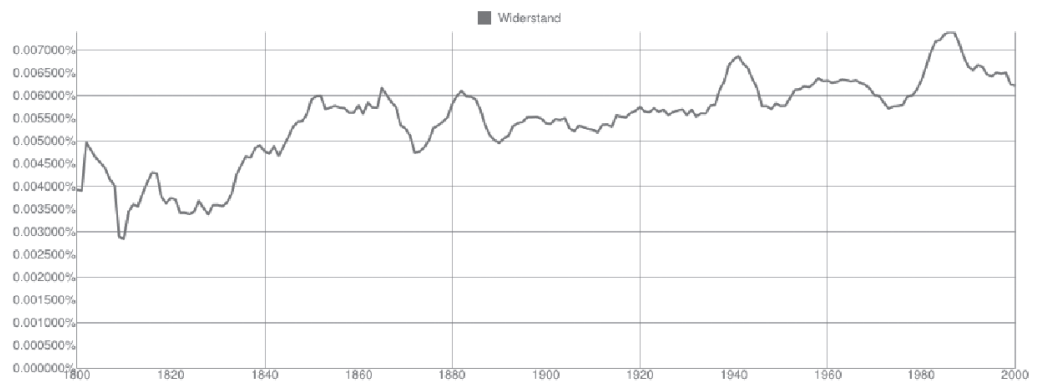


ChInÊS SIMPLIFICADO

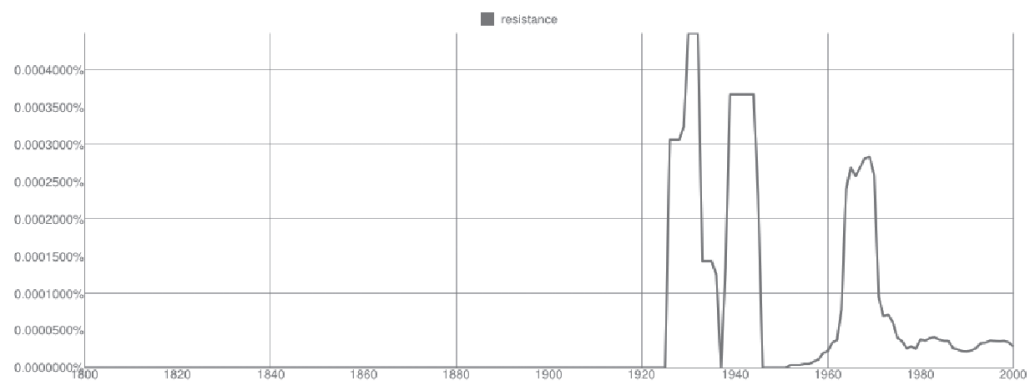

HeBRAICO

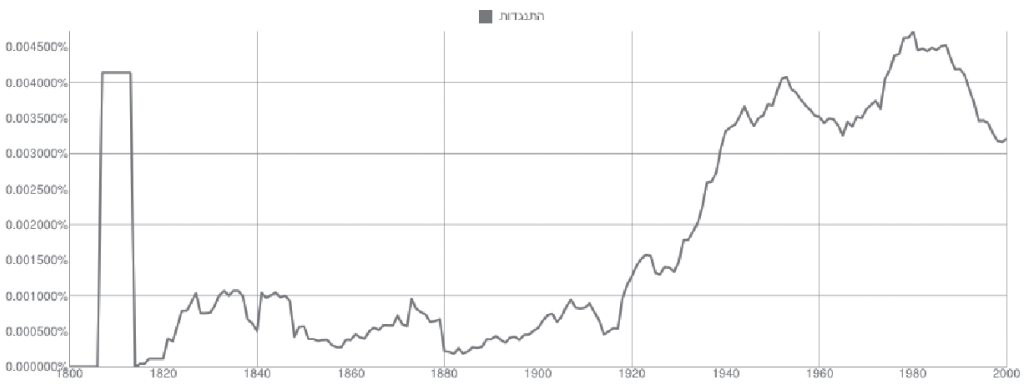

\section{O quarto verbete é luta.}

INGLÊS

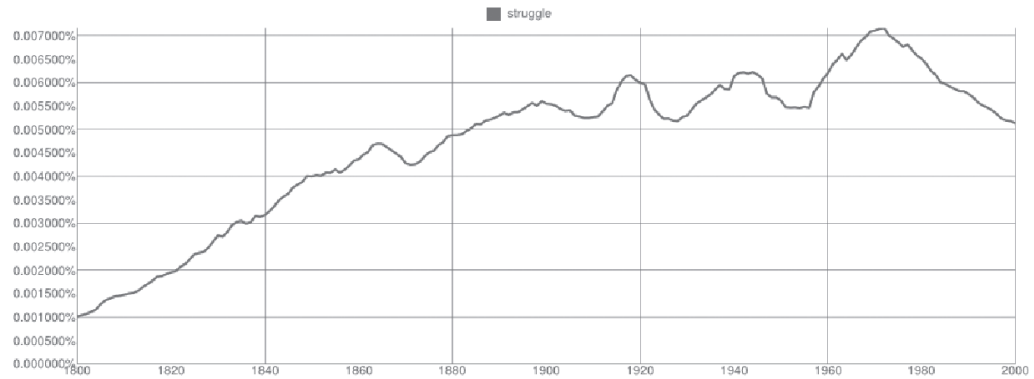


FRANCÊS

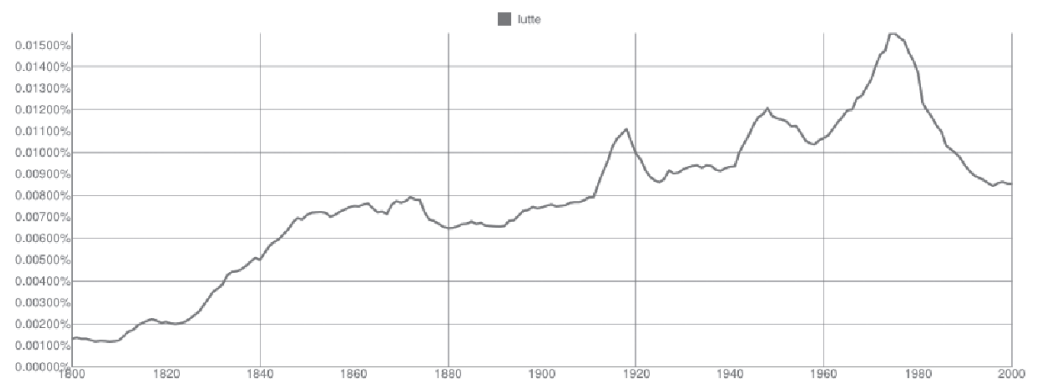

Alemão

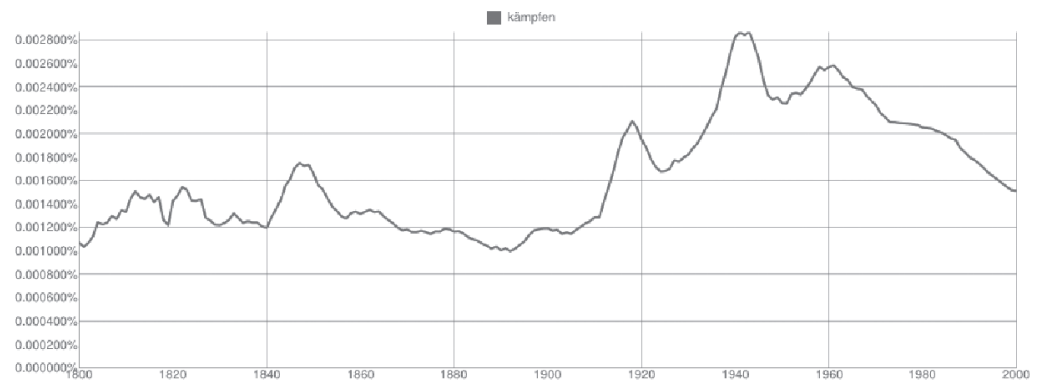

ESPANHOL

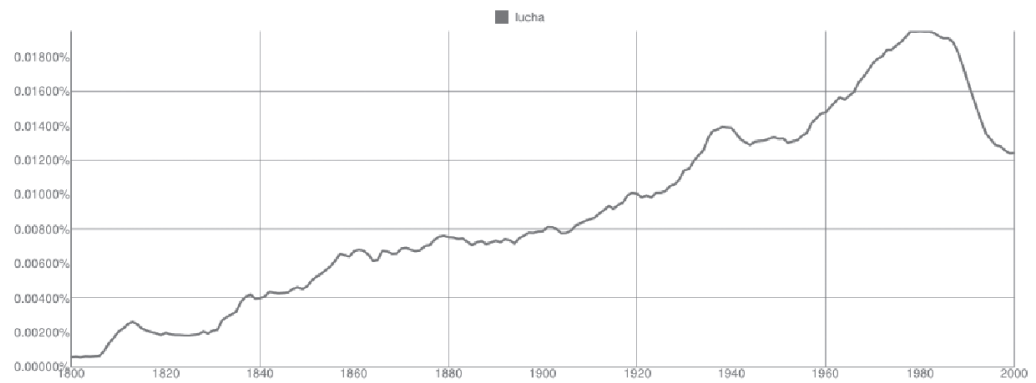


CHINÊS (SIMPLIFICADO)

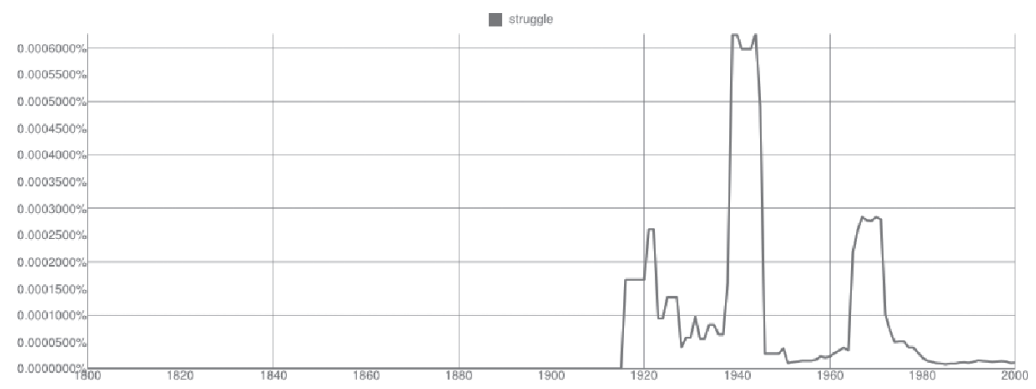

HEBRAICO

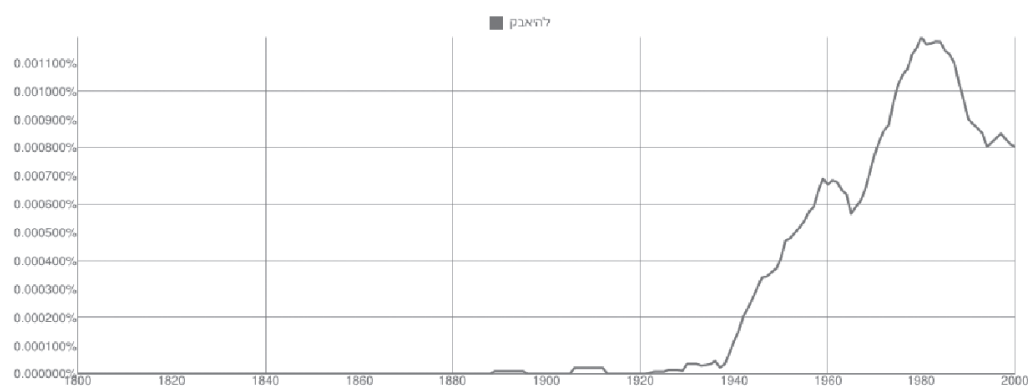

\section{Conclusão e discussão}

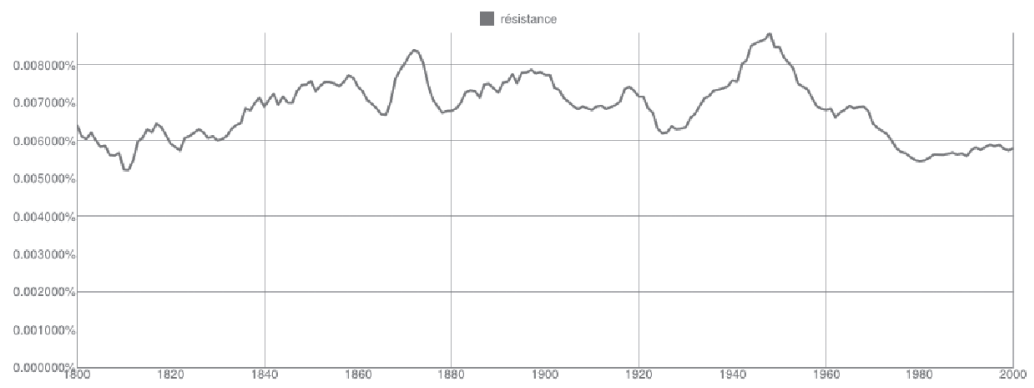

Considerando as sete tradições literárias examinadas, pode- se afirmar que entre os quatro verbetes mais frequentes nos comunicados políticos dos Montoneros e do Baader-Meinhof (revolucionário, luta, resistência e povo) o mais forte é o vocábulo 
'revolucionário'. Há marcante ascensão de sua frequência nas obras publicadas em inglês, francês, alemão e espanhol a partir de 1960. Este interesse se esgota até 1980, ano no qual - considerando estas literaturas - parece ter havido de fato um esfriamento 'intelectual' do interesse por estes temas. Em chinês há um curto período - o relativo à revolução cultural - que enfatizou não só este vocábulo como também 'luta', 'povo' e 'resistência'. No entanto, este interesse também desaquece rapidamente antes ainda do fim da década de 60 nesta tradição literária. Enquanto os grupos rebelados festejavam no Ocidente, em seus gritos de guerra, a figura mágica do revolucionário, na Rússia o desinteresse pelo mesmo aumenta exatamente no início dos anos 60 . Como era de se esperar, na conturbada França dos anos 60 a frequência do termo 'luta' cresce nesta década e perdura até 1980. Isso também ocorre em outras tradições literárias, à exceção da alemã e russa. No entanto, ele desaquece de uma forma geral a partir dos anos 80. 'Povo' é marcador retórico tardio na literatura russa, atormentada a partir da década de 1980 não pela utopia comunista, mas sim pela liberal. Nas demais tradições não há mudanças abruptas na sua frequência nos anos 60. Na literatura em inglês, a frequência de 'luta' foi sempre alta, sem alteração abrupta naquela década. Em francês, a frequência deste verbete estava caindo desde 1840. Queda similar ocorre em alemão desde 1950. A exceção a esta tendência é a literatura hebraica que revela interesse inusitado por este vocábulo desde 1800 . Isso se deve, muito provavelmente, às angústias históricas deste grupo humano desde o alvorecer da modernidade. 'Resistência' é outro termo que não ecoa nos escritos dos anos 60 em diante nas obras publicadas em russo, em espanhol e em francês (que testemunha alta frequência pelo termo desde 1800, mas que decai a partir dos anos 50). A literatura hebraica destoa aqui também sendo marcante o interesse pelo tema em sua literatura na década de 1960 .

A verdade é que ao contrário do que propunha a teoria da "Propaganda pelos Fatos", desde os tempos da militância anarquista a violência política moderna tem sido acompanhada por palavras, muitas palavras. Elas puseram em prática a recomen- 
dação de Johann Most (1846-1906), o editor e político alemão-americano que popularizou este conceito (1980). Em sua época ele falava da necessidade de distribuir posters para explicar as razões dos ataques que os militantes rebelados e radicalizados praticavam. Nos anos 60 , como se viu, foram os comunicados oficiais dos grupos políticos de esquerda e não posters que tentaram justificar ataques similares.

O exame comparado entre os verbetes mais frequentes nestes manifestos e as sete tradições literárias além de mostrar, como referido, haver uma dissonância entre os marcadores da retórica política dos jovens rebelados [e armados] dos anos 60 e o clima intelectual do período também mostra que os quatro marcadores retóricos mais frequentes dos comunicados políticos diferem em suas frequências internas nas sete tradições literárias examinadas. Em inglês e francês, o interesse maior é pelo 'povo'. Em alemão e espanhol é pela 'luta'. Na China destaca-se o 'revolucionário', mesmo assim somente por um brevíssimo período de tempo. Em geral, a frequência de todos estes vocábulos nestas tradições literárias é baixa, e em alguns casos baixíssima. Curiosamente observa-se também que de forma geral é exatamente a partir dos anos 60 que ocorre internamente nestas tradições literárias queda no interesse intelectual por vários destes temas. Ou seja, estes verbetes da retórica política dos Montoneros e do grupo Baader-Meinhof em geral não ecoam nas tradições culturais examinadas. Termos e conceitos mais significativos e marcantes como é o caso de 'direitos humanos' representam melhor o espírito deste novo tempo do que os quatro evocados nos manifestos rebeldes dos anos 60. Os 'direitos humanos' embora tenham se consolidado na 'Declaração Universal' promulgada na ONU em 1949 passaram a marcar retoricamente o 'espírito do tempo' somente a partir da década de 70. Os gráficos abaixo documentam esta alteração do clima de opinião pública mundial que se viu sensibilizado pela luta em favor dos direitos civis dos negros americanos, contra o apartheid na África do Sul e em favor dos refuseniks na União Soviética. 
AlemÃo

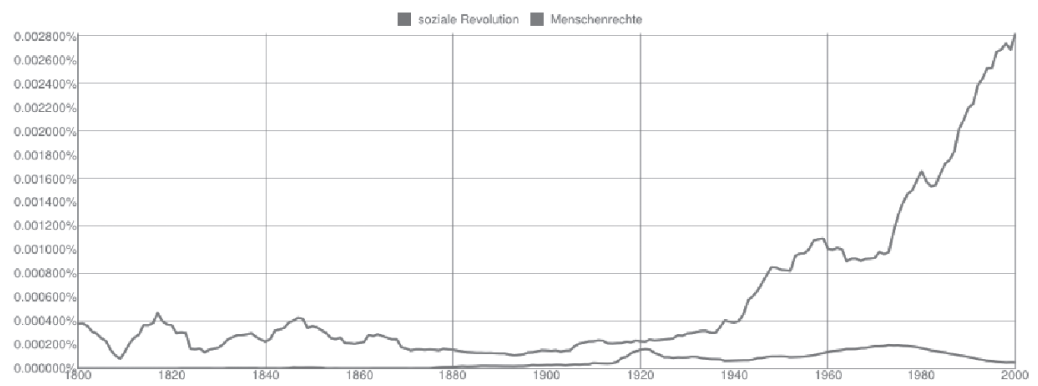

ESPANHOL

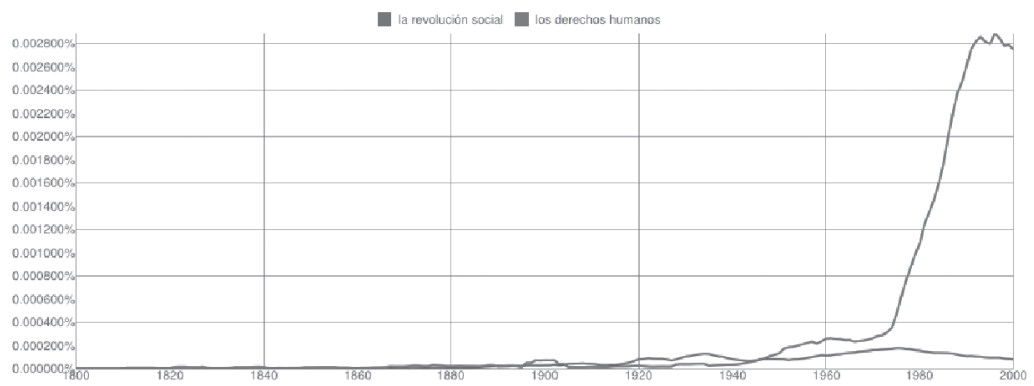

FRANCÊS

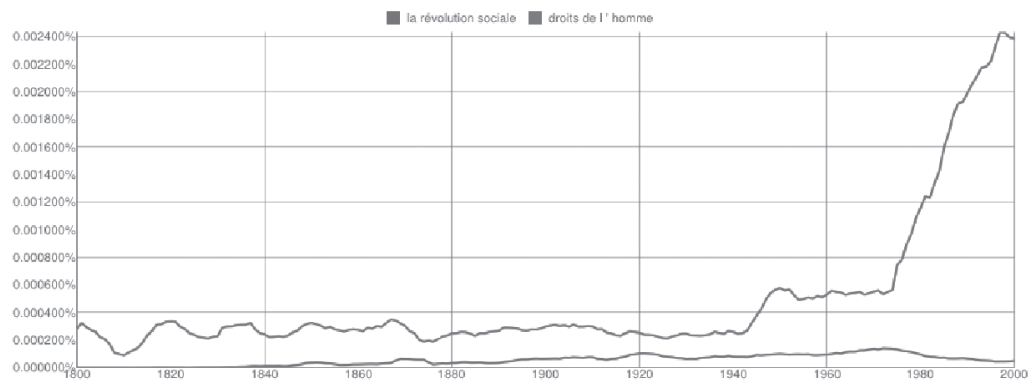


Hebraico

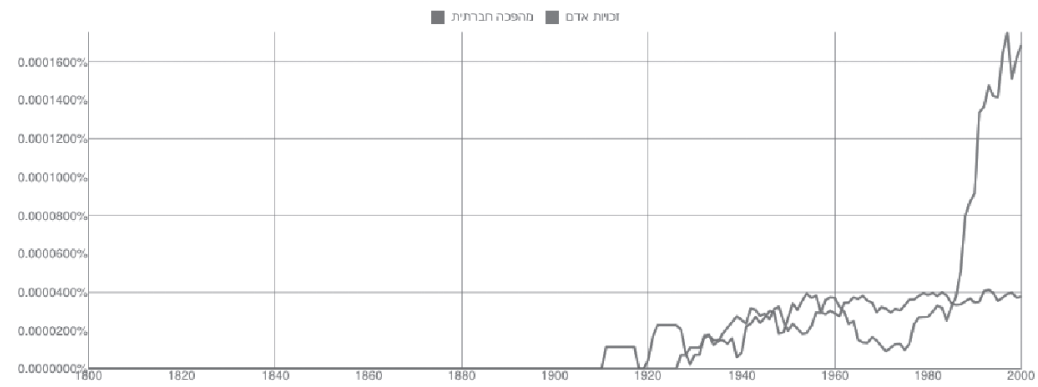

INGLÊS

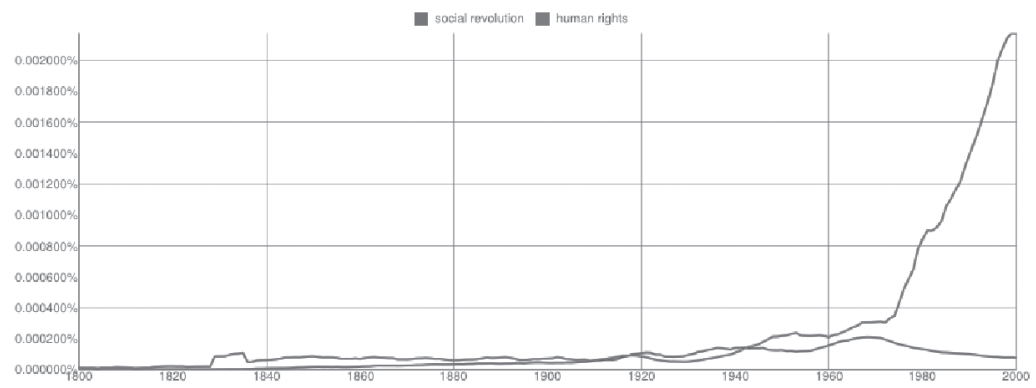

Russo

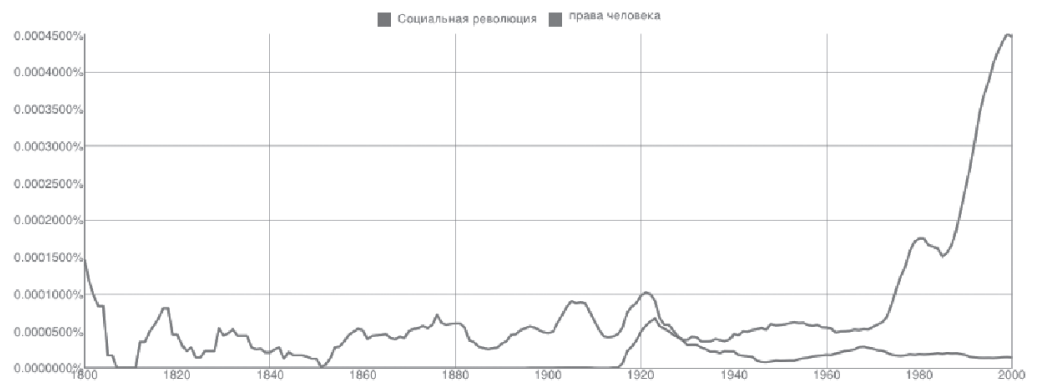




\section{Referências}

AL-MADINA al-Fadila. Al farabi on the perfect state: Abu Nasr Al Farabi's Mabadi' Ara Ahl Al-Madina Al-Fadil. London: Oxford University Press, 1985.

ANDRAE, Johann V. Christianopolis. International Archives of the History of Ideas, Dordrecht, London, v.162, 1999.

BACON, Sir Francis. The new atlantis and the great instauration. Arlington Heights, III: H. Davidson, 1989.

CALLENBACH, Ernest. Ecotopia. California: Heyday, 1975.

CAMPANELLA, Tomás. A cidade do sol. Lisboa: Guimarães, 1990.

DICKSON, Donald R. The Tessera of Antilia: utopian brotherhoods \& secret societies in the early seventeenth century. Brill's Studies in Intellectual History, Cologne / New York, v. 88, 1998.

HILTON, James. Horizonte perdido. São Paulo: Abril Cultural, 1980.

HOLLANDER, Paul. Political pilgrims: Western Intellectuals in Search of the Good Society. California: Transaction Publisher. 1997.

KUMAR, K. Utopia and anti-utopia in modern times. Oxford: Blackwell, 1987.

LANDAUER, Gustav. Revolution and other writings. A political reader. California: PM Press, 2010.

MANUEL, Frank E.; FRITZIE P. Manuel. Utopian thought in the western world. Cambridge: Mass, 1979.

MORE, Thomas. Utopia. São Paulo: Escritura, 2003.

MOYN, Samuel. The last utopia: human rights in history. Harvard: The Belknap Press of Harvard University Press, 2010.

NISBETT, Richard. Geography of thought. New York /London / Toronto / Sydney: Free Press, 2004.

PIERCY, Marge. Women on the edge of time. Minessota: Fawcett, 1959. 
TEUVO, Peltoniemi. Finnish utopian settlements in North America. Trabalho apresentado no Third Finn Forum, 5-8 de setembro, 1984, Turku, Finland. Disponível em: http://www.sosiomedia.fi/utopia/na_settlements.pdf.

TAO, Yuanming. The selected poems of T'ao Ch'ien. Copper Canyon Press, 1993.

TRAUTMANN, Frederic Trautmann. The voice of terror: a biography of Johann Most. Westport: Greenwood Press, 1980.

VANCE, Jack. Big planet. [s..1]: Gollancz, 2002.

VIRGILIO. Eclogas. Lisboa: INCM,1959.

WELLS, H.G. A moderna utopia (1905). [s.1.]: Great Space, 2011.

WRIGHT, Austin Tappan. Islandia. [s.1.]: Overlook, 2006.

YUANMIG, Tao. The selected poems of T'ao Ch'ien. Copper: CommonPress, 1993.

Recebido em 5.12.2011

Aceito em: 25.4.2012 